\title{
Has the Digital Economy Changed the Urban Network Structure in China?-Based on the Analysis of China's Top 500 New Economy Enterprises in 2020
}

\author{
Bo Chen and Huasheng Zhu *(D)
}

check for updates

Citation: Chen, B.; Zhu, H. Has the Digital Economy Changed the Urban Network Structure in China?-

Based on the Analysis of China's Top 500 New Economy Enterprises in 2020. Sustainability 2022, 14, 150. https://doi.org/10.3390/su14010150 Academic Editor: Antonella Petrillo

Received: 20 November 2021 Accepted: 21 December 2021

Published: 23 December 2021

Publisher's Note: MDPI stays neutral with regard to jurisdictional claims in published maps and institutional affiliations.

Copyright: (C) 2021 by the authors. Licensee MDPI, Basel, Switzerland. This article is an open access article distributed under the terms and conditions of the Creative Commons Attribution (CC BY) license (https:// creativecommons.org/licenses/by/ $4.0 /)$.
Faculty of Geographical Science, Beijing Normal University, Beijing 100875, China; bchen20@mail.bnu.edu.cn

* Correspondence: zhuhs@bnu.edu.cn

\begin{abstract}
The rapid development of the new generation of information technology makes digital enterprises and the digital economy important forces in promoting the sustainable growth of the world economy. Under the influence of the digital economy, the original urban network may undergo drastic changes. There have been studies that have arrived at conflicting conclusions. This paper primarily illustrates whether or not the digital economy has changed the urban network structure. China's digital economy is developing rapidly, becoming a new engine for the highquality development of the Chinese economy. Therefore, this paper demonstrates the impact of China's digital economy on the urban network structure by using data from China's Top 500 New Economy Enterprises in 2020 and the headquarter-subsidiary ownership method. The results show that (1) China's urban network has changed significantly. Compared with APS enterprises and listed companies, the urban network of the digital economy has become more polarized, and Beijing has become the absolute control center. (2) Chinese cities have been reshuffled in the era of the digital economy. Beijing, Hangzhou, and Chengdu, with their industrial foundations in the digital economy, have performed better within the network. Simultaneously, some heavily industrialized cities, such as Wuhan, Shenyang, and Chongqing, have been declining due to the difficulties associated with transformation. (3) Although the digital economy has reshaped China's urban network structure to a certain extent, the original urban pattern still plays a dominant role in the new system. The network spatial pattern of dense east and sparse west still exists, and provincial capitals and subprovincial cities still play a more significant role in the network than ordinary cities. (4) Network diffusion is typically a hierarchical diffusion between core nodes. Geographical proximity has a low constraint on network diffusion, and subsidiaries expand outward through hierarchical diffusion.
\end{abstract}

Keywords: digital economy; digital technology; new economy enterprises; urban networks; China

\section{Introduction}

As globalization increases connections among cities worldwide, these cities have become increasingly dependent on their relationships with other cities [1]. In particular, some cities with global influence, such as New York and London, have been linked to a world city network [2]. Thus, the last several decades have witnessed a shift in urban studies reflected by a growing research focus on urban networks. As a result, a large amount of literature has emerged, measuring urban networks based on diverse methods at multiple scales using corporate networks, infrastructure networks, railway and airline flows, and so forth [2-9]. In actuality, cross-regional firms are important actors in the formation of urban networks, and their internal organization relationships provide a perspective for urban network research. Moreover, firms' expansion to some burgeoning industries are also considered as an important actor for the dynamics of a city so as to provide a signal of the dynamics of urban networks $[10,11]$.

Networks of APS firms and the Fortune 500 companies have been widely used to measure urban networks at varied scales [2-4,8]. Studies of urban networks from the 
perspective of enterprise linkages are becoming increasingly prevalent in urban networks research; existing literature has explored the urban network constructed by film [12], energy [13], and so on. However, few studies have examined the connections and network between cities from the perspective of digital enterprise networks. The significance of studying urban networks based on digital enterprises lies in, firstly, that digital technology is integrating into all aspects of urban production and life [14-17], and that digital enterprises are rising rapidly, According to the ranking of the world's top 500 most valuable brands released by the British brand financial consulting company (Brand Finance, a British brand financial consulting firm, is a global independent third-party brand valuation and consulting firm headquartered in London. The company measures corporate brand value from the dimensions of existing performance, customer evaluation and future expectations by consulting public information on the official websites of listed companies, purchasing market performance data provided by companies, investigating consumer impressions and obtaining licensing-related data, and regularly launches the Top 500 Global Most Valuable Brands every year) in 2020, Amazon, Google, and Apple were ranked in the top three, and Microsoft, Huawei, Samsung, and other companies were among the top ten. Digital economy has become an important driving force for the development of the world economy, and the world economy is showing a trend of transition to "digital economy" [18]. Secondly, the digital economy becomes a new round of urban competition which may cause changes to occur in the original urban system [19-21]. In some cities, because there is no opportunity to lose competitiveness, and some cities become the digital economy "hot spots", attracting a large number of digital economy activity and, thus, fierce competition in the city. Lastly, Negroponte states "The post-information age will remove the limitations of geography. Digital living will include less and less dependence upon being in a specific place at a specific time, and the transmission of place itself will start to become possible" [22]. Cairncross even suggested a "death of distance" hypothesis [23], but this view is opposed by geographers. Because the high fixed input cost of information infrastructure and face-to-face communication can obtain knowledge rooted in space [24,25], the digital economy needs agglomeration. It can be found that the spatial organization model of digital enterprises and traditional enterprises may be different. Enterprise location choice is the basis of the formation of urban networks [9]. Will the digital economy change the original urban network? That is what we have focused on.

To answer this question, this article chose China as the case region for the following reasons. First, China's digital economy is developing rapidly and has become a new engine for economic growth. According to the White Paper on China's Digital Economy Development (2020) released by The China Academy of Information and Communications Technology, the added value of China's digital economy reached USD 35.8 trillion in 2019 and accounted for $36.2 \%$ of China's GDP. It has played an important role in promoting consumption, innovation, entrepreneurship, and value-chain reconstruction [26]. Second, the digital economy has become a new round of urban competition in China. In order to win this competition, various cities have formulated digital economic development strategies in order to establish digital economy agglomeration and attract large digital economic enterprises to build subsidiaries here; these features connect cities through the internal organization of digital economic enterprises [27]. Third, China's economic development has been unbalanced due to deep-rooted historical, institutional, and natural reasons, and the eastern coastal areas have become the center of economic growth [28]. As a result, APS enterprises, listed companies, and Fortune 500 enterprises all form a network pattern with coastal and resource orientations [29]. The digital economy is likely to break this pattern, and this is due to the fact that the digital economy takes data as primary productivity; this data has the characteristics of breaking through the barriers of time and space distance, and a digital platform can enable more cities and small and medium-sized enterprises to participate in it, with the possibility of changing the original urban network. Based on the above three points, it is clear to see that China is undergoing a transformation of the digital economy, digital economic enterprises are connecting cities, 
and the urban network trend is towards change. Therefore, it is reasonable and logical to take China as a case study to discover whether or not the digital economy has changed the original urban network. Cao [27] explored China's urban networks based on data from China's Top 100 Internet Companies and found that the networks were flatter. However, Zhou et al. [30] studied the hierarchical city system of China's interconnected economy and found that the urban system presented a trend of spatial polarization. Therefore, the impact of the digital economy on China's urban networks still needs to be tested through solid empirical research.

As the leader of China's digital economy, China's top 500 new economy enterprises can represent the digital economy to a certain extent. In order to expand the market and enhance their competitive advantage, the top 500 enterprises of the new economy have made careful strategic analysis; appropriate cities or regions will be selected to set up subsidiaries [27]. Studies have shown that there is frequent factor flow between the headquarters and subsidiaries of new economy enterprises, and the flow between subsidiaries is relatively weak because data, knowledge, and information, as important production factors of new economy enterprises, belong to the category of vertical relationship [7]. An association network is formed between enterprise headquarters and subsidiaries, combined with embeddedness theory [31,32], so that production factors can flow smoothly between cities [3], which will affect the structure of urban system, thus forming an important entry point for the study of urban network. The relationship between the headquarters and subsidiaries of the top 500 enterprises in the new economy exists in data, knowledge, personnel, capital, and many other aspects. The factor flow between cross-regional headquarters and subsidiaries helps to reveal the functional relationship between cities [33]. The interlocking network model and headquarter-subsidiary ownership method are two methods to study urban networks from the perspective of enterprise networks. The interlocking network model assumes that subsidiaries also have connections [2,4], and the headquarter-subsidiary ownership method believes that there are few connections between subsidiaries $[3,6]$. Therefore, the Chinese case study in this paper is based on the new economy top 500 enterprises, using the headquarter-subsidiary ownership method to study China's urban network of digital economy. The questions above have been divided into three aspects: (1) Has the digital economic enterprise network changed the existing urban network in China? (2) If yes, has this change made China's digital economic urban network more concentrated or flatter in comparison to APS enterprises and industry-wide enterprise networks? (3) Which cities are doing better or worse within the digital economic networks?

The rest of this paper is organized as follows. The second part is a review of existing research on links between cities; we identify the need to study digital economic links. The third part is an introduction of data sources and empirical methods in detail, and it further explains the top 500 enterprises in this new economy. The fourth part mainly analyzes the characteristics of the digital economic urban network, including urban systems and network structures. The fifth part is a comparison of the spatial structure of the three most developed urban agglomerations in China. The sixth part draws the conclusion.

\section{An Urban Network Based on Intrafirm Connections}

The study of an urban network originates from Western scholars' interests in the world urban network. In the 1960s, Hall first proposed the standard of a world city from the perspective of urban functions [34]. Friedmann (1986) proposed the world city hypothesis, which emphasizes that world cities are important nodes affecting global capital flow [35]. Sassen (1991) advanced the concept of a global city [36]. Her belief is that advanced producer services (APS) are mainly concentrated in global cities, and a few cities such as New York, London, and Tokyo have become global strategic control centers. Castells (1996) offered the theory of flow space [37], and he was convinced that the wide application of information technology had brought about spacetime compression, and flow space had gradually replaced place space. As the main form of spatial organization, the theory of flow space undoubtedly provides a theoretical framework and an important starting 
point for urban network research. Based on the related theories of Sassen and Castells, Taylor (2001) normalized the world city network as the interlocking network model. The global strategy of APS stimulated the formation of the world city network, and the flow of information, knowledge, capital, and labor in the APS office network shaped the world city network [38]. Urban system research has gradually shifted from an attribute perspective to a relationship perspective.

Based on the distribution data of APS, Globalization and World Cities (GaWC) has conducted a large number of empirical studies on the world urban network through the interlocking network model $[2,4,39,40]$. However, since the interlocking network model has been used to translate the enterprise network into the city network, a large number of scholars have questioned the applicability of the interlocking network model. In 2012, at the Annual Meeting of the American Geographical Society (AAG), a panel discussion was organized on the function, application, and criticism of the GaWC linkage network model. Rozenblat et al. argued that interfirm connections within a group exist only in some subsidiaries, and the rich intercity interactions generated by the interlocking network model lead to a flat network that hides true polarization [41]. Kratke countered that the linkage model ignores the intercity connections built by firms in other industries, especially in developing and newly industrialized countries where the real economy, such as manufacturing, is indispensable and should not be excluded from building networks [42].

The headquarter-subsidiary ownership method avoids the issues listed above to a certain extent. Compared with the interlocking network model, which assumes that all subsidiaries are connected, the headquarter-subsidiary ownership method is a more direct and accurate method. Its main advantage lies in transforming tangible intracompany connections into intercity connections [3,43]. Moreover, the enterprise network focusing on the entire industry is better able to reflect the panorama of urban connections [44]. Therefore, the headquarter-subsidiary ownership method has gradually been more widely used in urban network research. Alderson used the location information of headquarters and subsidiaries of Fortune 500 multinational companies to measure centrality in three ways for 3692 cities. This study found that a few cities monopolized power and prestige, and that the world urban system has formed quite a strong hierarchy, including the fact that Tokyo's power has been much stronger than is often portrayed [3]. The Wall and Knaap improved the headquarter-subsidiary ownership method, and the enterprise ownership has now been divided into five levels, and in contrast to the APS and industry enterprises of the world city network, the study found that an APS company, rather than relying on another industrial department, has a strong consistency between them. However, different categories of the corporate network lead to different cities and intercity network configurations [44]. With the continuous deepening and improvement of research, urban network research has also shown an expansion of data sources in recent years. The film industry [12], energy industry [13], and other data sources have been used to explore the urban network. This has made it conducive to clarify the role of cities in multiple networks.

The rapid rise of Chinese cities has attracted the extensive attention of scholars. The last decade has witnessed growing literature on China's urban networks. Research on the urban network has been based on enterprise connections. It typically focuses on three scales. Firstly, it explains how Chinese cities position themselves in the world urban network on a global scale. For example, Derudder et al. explored how Chinese cities connect with the world urban network by using GaWC data. He found that Hong Kong, Shanghai, and Beijing are now more important than ever in the world's urban network. Today, Shanghai is more connected to the most important world-class cities, such as London and New York, while Beijing is better connected to political world-class cities such as Washington and Brussels, as well as other Asian Pacific cities [4]. Csomós found that, with its rich corporate headquarters, Beijing has become the main command and control center of the world economy [45]. Raz'niak's ranking of world economic centers proves Beijing's leading position among inland cities in China [46]. 
Second, the scale of the country's urban network research is greater; the opinion of Zhao and others is that GaWC insufficiently built the APS enterprise database involved in the establishment of subsidiaries offices in China; this insufficiency did not adequately reflect the real situation of China's urban network. For this reason, they built a public APS database in China that illustrates the characteristics of the Chinese urban network. The results show that Beijing and Shanghai have become the principal core cities, the coastal urban agglomeration has become the major agglomeration area of producer services, and most of the other cities are located along the periphery with a relatively low connection degree of producer services. Additionally, they found that, unlike other studies asserting that Shanghai has surpassed Beijing in the world city network, Beijing had taken the lead in the national APS enterprise urban network [29]. A study by Pan et al. found that Beijing has much greater influence than any other city, becoming the command and financial center of the mainland China city network [8]. As far as Chinese cities are concerned, the development of the real economy, including manufacturing, remains indispensable, so it is a one-sided approach to focus only on the urban network formed by APS enterprises [7]. Zhao et al., basing his research on 102 Chinese global Fortune 500 enterprises, used the eclectic network model to explore the structure of the Chinese urban network. This research demonstrates that Beijing has become the absolute network center, and the urban network connection has developed an obvious administrative center orientation, coastal orientation, and resource orientation [47]. As large enterprises prefer to establish subsidiaries in large cities, small and medium-sized cities are ignored. Jiang et al. used listed companies' data to conduct a nationwide urban network study and found that Beijing, Shanghai, and Shenzhen are in the first-tier network [48].

Urban agglomerations are also an important scale for network research. Li et al. studied the network structure of urban agglomerations in China based on Fortune 500 enterprises and found that the eastern coastal urban agglomerations present a phenomenon of that of a small group network, while the characteristics of small group networks in the central and western urban agglomerations are not obvious. Among them, the small group network phenomena in the Beijing-Tianjin-Hebei urban agglomeration are the most significant, and the network densities between cities in urban agglomerations are higher than the external connections. The economic connections of urban agglomerations in the Pearl River Delta and Yangtze River Delta largely come from connections with other urban agglomerations [49]. Zhao et al. asserted that the Beijing-Tianjin-Hebei urban agglomeration presents a dual-core network structure dominated by Beijing and Tianjin, and Beijing enterprises have shown a strong tendency of setting up subsidiaries outside the city. The Yangtze River Delta urban agglomeration has formed a network structure with Shanghai as the hub and Suzhou, Hangzhou, Ningbo, Nanjing, and Wuxi as the satellites. Shanghai has the largest number of cross-city enterprises, and they show close corporate ties to other cities in their urban agglomeration. Within the Pearl River Delta urban agglomeration, the urban network has the structural characteristics of integration. Shenzhen has the largest number of cross-city enterprises. Shenzhen does not just have major hubs within the city cluster, but also has a more prominent extroverted corporate headquarters control function than Guangzhou [50].

Due to the introduction and large-scale penetration of information and communication technology (ICT) in all economic sectors, scholars began to pay attention to the impact of digital economy on urban linkages and urban systems. As the birthplace of the Internet, the United States was the first to study the urban network structure of digital economy based on network infrastructure. Townsend et al. explored the connectivity and accessibility of the node city information network based on the infrastructure and confirmed that there are spatial imbalances in the accessibility of information, and the gap is widening. San Francisco has become the new center of the American urban system in the Internet era $[19,20]$. Zook studied the urban hierarchical system from the network perspective using Internet domain name data, which provides a micro perspective. The same conclusion was reached; the San Francisco metropolitan area is the network production and consumption 
center second only to New York [21]. As the Internet technology revolution swept into China, China's network city hierarchy has attracted scholars' attention [51]. Wang et al. originally focused on the accessibility of urban network infrastructure and pointed out that China's network infrastructure tends to be balanced. Beijing, Shanghai, and Guangzhou are the core cities connected by the network, and node accessibility follows the original city hierarchy [52]. Tranos et al. used IP link data to study the network connection between Chinese cities and the world, as well as the characteristics of China's Internet connection. Beijing is the main anchor point of China's IP network and global IP network, the network connectivity of Chinese cities is highly unequal, and the inequality increases with the passage of time, resulting in the phenomenon of "the rich get richer" [18].

With the rapid rise of digital enterprises, the result is that digital enterprises provide digital platforms and digital tools (including software) for digital economy and become the main promoters of digital economy (according to the definition of World Subsidiary Report 2017 (UNC-TAD, 2017), multinational companies in the digital economy include digital technology multinational companies (Internet platforms, digital content, e-commerce and digital solutions multinational companies) and Information and communication technology (ICT) multinational companies that provide infrastructure and hardware for the digital economy. Page 167 of World Economic Report 2017 (English version). In the field of international economy, the rapid growth of multinational enterprises in the digital economy has become an important trend in the development of global multinational enterprises. In the context of the continued downturn of global FDI, the external expansion of multinational enterprises in the digital economy has maintained a strong growth. From 2010 to 2015, among the top 100 global multinational enterprises of the United Nations Trade and Development Organization, the number of digital economy science and technology enterprises and ICT multinational enterprises increased from 13 to 19, the proportion of their total assets and sales in the top 100 also increased from $10 \%$ to about $20 \%$, and the market value accounted for $26 \%$ of the top 100 . The assets of digital technology multinational enterprises are growing at an annual rate of $10 \%$, while the assets growth of traditional multinational enterprises is almost stagnant (UNCTAD, World Subsidiary Report 2017). The rapid expansion of digital enterprises around the world connects global cities.

With the help of various emerging technologies such as mobile Internet, big data, artificial intelligence, and cloud computing, China's digital enterprises have experienced geometric growth in digital business. At the beginning of Taobao's establishment in 2003, there was basically no transaction. The retail sales reached CNY 20 billion in 2006, exceeded CNY 100 billion in 2008, and exceeded CNY 3 trillion for the first time in 2016, which is comparable to Walmart, the world's largest traditional retail enterprise. In terms of travel industry, there are about 2 million taxi drivers in China, while DiDi has more than 15 million registered drivers (Alibaba Research Institute, Digital Economy 2.0 Report, January 2017, http: / / www.aliresearch.com/blog/article/detail/id/21213.html, accessed on 13 December 2021). Digital enterprises show strong market expansion ability, can organize and mobilize market resources in a wider range, connect small and mediumsized enterprises with cities, and form China's urban network of digital economy. Some scholars have begun to pay attention to China's urban network structure under digital enterprises. Cao et al. explored China's urban network using the data from China's Top 100 Internet Enterprises in 2016 and found that the network was flatter [27]. Beijing, Hangzhou, and Shenzhen occupy the main links among Chinese cities from the perspective of internet enterprises. Shanghai does not dominate the urban network of internet companies. Zhou et al. explored the urban hierarchy of China's Internet economy and found that contributions to the digital economy of the city process spatial agglomeration of economic elements. This caused the spatial polarization trend of urban systems. Beijing is located in the first level, and its digital economic development index is far more than that of other Chinese cities, including the second-tier cities of Shanghai, Shenzhen, and Hangzhou [29]. It can be seen that the impact of digital economy on China's urban network has not formed 
a consistent conclusion, and the impact of digital economy on urban network still needs solid empirical research.

In short, urban network research based on enterprise networks has increased significantly in China and the world. Due to the important role of Fortune 500 enterprises, APS, and listed companies in the economy, they are widely used in urban network research. Digital enterprises and digital economy are rising, which may reshape the urban network structure. At present, there are few studies on the urban network of digital enterprises, and the existing studies have not reached an agreed conclusion; therefore, it is necessary to study the urban network of digital economy. Thus, based on the new economic top 500 enterprises, this paper investigates the urban network of the digital economy. It provides an empirical case for the impact of the digital economy on the Chinese urban network by comparing it with APS enterprises, Fortune 500 companies, and listed companies.

\section{Data and Methodology}

\subsection{Data Description}

Companies in the top 500 of China's New Economy released by the China Enterprise Evaluation Association (China Enterprise Evaluation Association (CEEA), founded by the Development Research Center of the State Council in 1991, is the only state-level corporate organization registered by the Ministry of Civil Affairs and qualified for enterprise evaluation. At the end of 1980s, CEEA was the first to evaluate Chinese enterprises. In conjunction with relevant ministries and com-missions of the State Council, CEEA issued "China's 500 largest industrial enterprises, best economic benefits, 500 Chinese construction industry and 500 Chinese service industry" for eight consecutive years according to international practice, and wrote a series of comprehensive and special analysis reports, which caused great repercussions at home and abroad) in 2020 were selected as research samples. We then selected companies with subsidiaries in two or more prefecture-level cities in mainland China. Mindfully, we deleted many subsidiaries belonging to the store level. In particular, the following should be noted:

(1) The China Enterprise Evaluation Association released the top 500 companies in the new economy with enterprise scale as the main sequence indicator; growth speed, profitability, technology drive, talent employment, and social public opinion were used as revised indicators.

(2) Enterprises in the new economy must meet the following conditions: First, they must have at least one of the following characteristics: (i) new industries directly created by the industrialization of the application of new technologies; (ii) new industries formed by traditional industries using modern information technology; (iii) new industries derived from scientific and technological achievements and information technology applications; (iv) business activities based on the Internet and information technology; (v) innovate production processes, business processes, service models, and product patterns; (vi) integrate internet and industrial innovation; (vii) integrate hardware into services; and (viii) provide one-stop services for consumption, entertainment, leisure and, services in modern life. Second, the proportion of the new economic business revenue is more than $50 \%$. Third, it already has a certain scale, about CNY 20 billion.

(3) In terms of industry classification, advanced manufacturing enterprises account for the highest proportion, reaching $51.2 \%$. These are followed by Internet and modern information technology service industries and enterprises with new life service activities; they account for $15.6 \%$ and $14.0 \%$, respectively.

\subsection{Methodology}

\subsubsection{Network Construction}

Cross-city data, information, personnel, and capital between enterprise departments in the new economy can promote the correlation between cities. Previous studies have shown that the cross-city elements of new economy enterprises mostly occur between headquarters and subsidiaries [7]. The reason is that data, knowledge, and information, as 
important production factors of new economy enterprises, belong to the category of vertical relationship, and the connection between subsidiaries is relatively weak. Therefore, this paper uses the headquarter-subsidiary ownership method [3], the headquarter-subsidiaries of the new economy top 500 are regarded as the "agent" of the city and applied to the research of China's urban network as a measurement index. The connection between cities is defined as

$$
F_{i j}=\sum w * f_{i j}
$$

wherein $F_{i j}$ represents the degree of connection between cities based on the new economic enterprises; $f_{i j}$ represents the information flow generated by the establishment of subsidiary in the $j$ city where the headquarters of the new economic enterprise is located in the $j$ city. In turn, $f_{j i}$. $w$ represents the weight of the strength of connections between different departments of the enterprise. We used three intensity levels to quantify the relationship strength between enterprise departments: research and development departments, regional companies, science and technology subsidiaries, etc. They are the core department, and they are most closely related to the factor flow of headquarters, so we assigned a relationship strength of 2. A general company responsible for sales and production has a relatively low degree of connection with it, so the relationship strength assigned is 1. For subenterprises which are not related to main businesses, such as those subsidiaries engaged in real estate, the relationship strength assigned is 0 .

The out-degree $\left(O_{i}\right)$ and in-degree $\left(O_{j}\right)$ of a city represent the outflow and inflow of city information, respectively, and represent the city's ability to control and attract information flow. Their calculation formula is as follows:

$$
\begin{aligned}
& O_{i}=\sum_{j} F_{i j} \\
& O_{j}=\sum_{i} F_{j i}
\end{aligned}
$$

Urban centrality $\left(N_{i}\right)$ does not include the direction of flow but measures the sum of urban I information flow. The higher the centrality of the city, the higher the city is in the core position of the information flow network. Conversely, the lower it is, the lower it is at the edge of the network. The formula is as follows:

$$
N_{i}=O_{i}+O_{j}
$$

\subsubsection{Network Analysis}

(1) Network density. Network density is an index that reflects the compactness of each node in the network: the stronger the correlation between the nodes in the network, the greater the network density. Network density is defined as the ratio of the actual relation number to the theoretical maximum relation number in the network, and its calculation formula is as follows:

$$
\mathrm{D}=L / n(n-1)
$$

where in D represents network density, $L$ represents the actual correlation coefficient contained in the network, and $n$ represents the number of network nodes. The range of network density $\mathrm{D}$ is $[0,1]$. The higher the $\mathrm{D}$ value is, the more frequent and extensive the relationship between cities is, and vice versa.

(2) Network assignment index. The network assignment index reflects the degree of cohesion of the subgroup of the network or the distribution degree of the whole network. It is an important index for the analysis of network structure. In this paper, the network assignment index was used to calculate whether the characteristics of the small group network of urban agglomeration were obvious or not. The calculation formula is as follows:

$$
E-I_{\text {index }}=E I-I L / E I+I L
$$

wherein EI represents the external relation number of urban agglomeration; IL represents the internal relations number of urban agglomeration. The value of $E-I_{\text {index }}$ index is in the range of $[-1,1]$, and the greater the value tends to be 1 indicates that a network 
relationship tends to occur outside the urban agglomeration. The greater the value tends to be 0 indicates that the external relations coefficient and internal relations coefficient of urban agglomeration are equal; this relationship tends to result in a random distribution. The more the value tends to -1 , the greater the indication that a network relationship mainly occurs within the urban agglomeration.

\section{Analysis of the Characteristics of China's Digital Economic City Network}

\subsection{Analysis of Node City Characteristics}

\subsubsection{Node City Hierarchy System}

Through the calculation of the centrality degree by implementing Formulas (1)-(4), it was found that there was a significant difference in the value of different cities, and it showed a decreasing trend of order-scale. Using ArcGIS 10.2 software and the natural breakpoint method, urban centrality was divided into five levels (Table 1). The first-tier cities only included Beijing, which is the national network contact center. The secondlevel cities involved Shenzhen, Hangzhou, and Shanghai; these are national network contact centers. Nanjing, Guangzhou, Chengdu, Changsha, and Tianjin were the thirdlevel nodes and are regional network contact centers. A total of 27 cities, such as Fuzhou, Wuhan, Urumqi, Hefei, and Shenyang, are at the fourth level, and are local contact centers. Meanwhile, 300 cities, such as Lanzhou, Guiyang, Yinchuan, and Zhongshan, are at the fifth level and are general contact nodes. The role of network connection is relatively weak. From the above five levels, Beijing, Shenzhen, Hangzhou, and Shanghai are the key nodes of urban network links.

Table 1. Hierarchical distribution of urban network in China from the perspective of enterprise connection in the new economy.

\begin{tabular}{|c|c|c|c|c|c|}
\hline Level & Cities & Measurements & Mean & Number & Proportion (\%) \\
\hline 1 & Beijing & 2989 & 2989 & 1 & 0.3 \\
\hline 2 & Shenzhen, Hangzhou, Shanghai & $976-1261$ & 1114 & 3 & 0.9 \\
\hline 3 & Nanjing, Guangzhou, Chengdu, Changsha, Tianjin & $161-330$ & 221 & 5 & 1.5 \\
\hline 4 & $\begin{array}{l}\text { Fuzhou, Wuhan, Urumqi, Hefei, Shenyang, Suzhou, Wuxi, Xi'an, Jinan, } \\
\text { Chongqing, Zhengzhou, Nanchang, Harbin, Kunming, Xiamen, } \\
\text { Qingdao, Shijiazhuang, Wenzhou, Changchun, Dongguan, Dalian, } \\
\text { Nanning, Ningbo, Taiyuan, Hohhot, Zhuhai, Nantong... }\end{array}$ & $57-137$ & 91 & 27 & 8 \\
\hline 5 & $\begin{array}{l}\text { Guiyang, Lanzhou, Foshan, Xining, Yinchuan, Zhongshan, Yantai, } \\
\text { Haikou, Xuzhou, Langfang, Weifang, Changzhou... }\end{array}$ & $2-54$ & 12 & 300 & 89.3 \\
\hline
\end{tabular}

First and foremost, it can be seen from the number of cities at different levels that the network polarization of digital economic cities is significant. There is only one city at the first level, three cities at the second level, and only five cities at the third level. Most cities are located at tier 5, which means that the core network was constructed by a few cities, and most cities are located at the edge of the network. In comparison with producer services and manufacturing cities, it was discovered that the structure of the urban network has changed significantly. Beijing, Hangzhou, Chengdu, and other cities have become more important within the network. On the contrary, the network status of some heavily industrial cities, such as Wuhan, Chongqing, Shenyang, Jinan, and others, showed a downward trend.

As a new economic form, the digital economy is in urgent need of policy support. Under China's institutional arrangements, Beijing is the political center of the country, and those locations of digital economic company headquarters in Beijing usually enjoy the support of policymakers [8]. Hangzhou's Project No. 1 policy is also an important step towards taking center stage in this era of the digital economy [53]. Thanks to Alibaba, Hangzhou's government has long recognized the promise of the digital economy. In Project No. 1, released in 2003, Hangzhou proposed to vigorously develop the digital economy to facilitate the rapid development of Hangzhou's digital economy. In recent years, Chengdu has successfully issued top-level designs, such as the Implementation Plan for Promoting the digital Economic development in Chengdu, Opinions on Creating a New Ecology, Developing a New Economy and Fostering a New Driving Force to guide the participation of market players and promote the rapid development of the digital economy in Chengdu [54]. 
As a knowledge economy, the digital economy has higher requirements on human capital. Due to the institutional arrangement of China [8], the administrative city center gathers countless resources, such as human and financial resources. This places the provincial capital and vice-provincial capital chiefly on the third and fourth floors. It is no secret that Western China suffers from a serious brain drain. This leaves provincial capitals in the west, such as Lanzhou, Yinchuan, and Guiyang, as mere general nodes of connection. The allure of Western China is made worse by the war for talent now underway in major cities. The shortage of human capital may be the key factor restricting the development of the digital economy in Western China [55,56].

\subsubsection{Classification of Node City Types}

A city controls the flow of information in two significant ways: attraction and radiation. The out-degree $\left(O_{i}\right)$ reflects the ability of the city to radiate outward, while the in-degree $\left(O_{j}\right)$ reflects the ability of the city to attract inward. The ratio of out-degree $\left(O_{i}\right)$ to in-degree $\left(O_{j}\right)$ is defined as equilibrium degree. The higher the value is, the stronger the radiation capacity of the city is, and the smaller the value is, the stronger the attraction ability of the city is. When the value tends to be 1 , it indicates that it is more balanced. According to the degree of equilibrium, cities are divided into extroverted type (equilibrium index $\geq 1.5$ ), equilibrium type $(0.5<$ equilibrium index $<1.5)$, and introverted type (equilibrium index $\leq 0.5)$.

As shown in Table 2, the number of export-oriented cities is relatively small, comprising Beijing, Shenzhen, Hangzhou, Shanghai, and Nanjing. These cities have a strong radiation power and are the control centers of the digital economic network. In particular, Beijing has set up subsidiary companies in the other 335 cities, showing super control. There are 16 balanced cities, and there are predominantly two types. The first is where out-degree $\left(O_{i}\right)$ and in-degree $\left(O_{j}\right)$ are relatively high, and the other is where both are relatively low. Guangzhou, Changsha, Tianjin, Fuzhou, Suzhou, Urumqi, Zhuhai, Wenzhou, and Wuxi belong to the former, while Ji'an, Yanbian, Longyan, and Langfang belong to the latter. The number of introverted cities is the highest, with a total of 315 of which 279 cities have an out-degree $\left(O_{j}\right)$ of 0 , thus indicating that these cities have not established external subenterprises and are passively embedded in the network. Most provincial capital cities also belong to the introverted type, and their equilibrium index is very small. The attraction capacity is much greater than the radiation capacity, indicating that within the perspective of the digital economy, regional central cities and surrounding small and medium-sized cities largely compete with each other, and their radiation driving effect is relatively small.

Table 2. Classification of Chinese cities based on equilibrium index.

\begin{tabular}{cl}
\hline Type & \multicolumn{1}{c}{ Cities } \\
\hline Extroverted & Beijing, Hangzhou, Shenzhen, Shanghai, Nanjing \\
Balanced & Gongyan, Wenzhou, Langfang, Yanbian Korean Autonomous Prefecture, Urumqi, Tianjin, Wuxi, \\
& Yunfu, Bengbu, Yantai, Shenyang, Hefei, Taizhou, Zhongshan, Xiamen, Huzhou, Taizhou, \\
& Ningde, Xingtai, Wuhu, Dongguan, Chengdu, Changzhou, Zhenjiang, Ganzhou, Shaoxing, \\
Shantou, Nantong, Jiaxing, Jinhua, Lianyungang, Wuhan, Meizhou, Qingdao, Jiangmen, Dalian, & 6.5 \\
Introverted & Huizhou, Quanzhou, Ningbo, Shijiazhuang, Harbin, Chongqing, Jinan, Xi'an ... \\
\hline
\end{tabular}

The equilibrium index is able to clearly reflect the city's external diffusion or inward attraction, but it masks its absolute ability of external diffusion and inward attraction. Therefore, the k-value clustering method was utilized to cluster the two values of each city into high and low levels. The cities were then divided into four categories: high attractionhigh radiation (I), high radiation-low attraction (II), low attraction-low radiation (III), and high attraction-low radiation (IV) (Figure 1). Beijing, Shenzhen, Hangzhou, and Shanghai are Class-I cities. This illustrates that these four cities are not only important diffusion centers, but also convergence centers, and the number of Class-II cities is 0 . This is an indication that high radiation cities have strong attraction and do not have high radiation and low attractiveness. The proportion of Class-III cities is very high, with a total of 303 . That is to say, most cities are at the edge of the network and are often embedded in the network through 1-2 branch subsidiaries. There are a total of 29 Class-IV cities, most of 
which are provincial capitals. Although their radiation capacity is limited, their ability to attract subsidiaries is stronger than that of ordinary cities, especially Chengdu, Wuhan, Nanjing, Xi'an, and other similar cities. This further proves that there is more competition between the core and the periphery, but core cities obviously have more advantages.

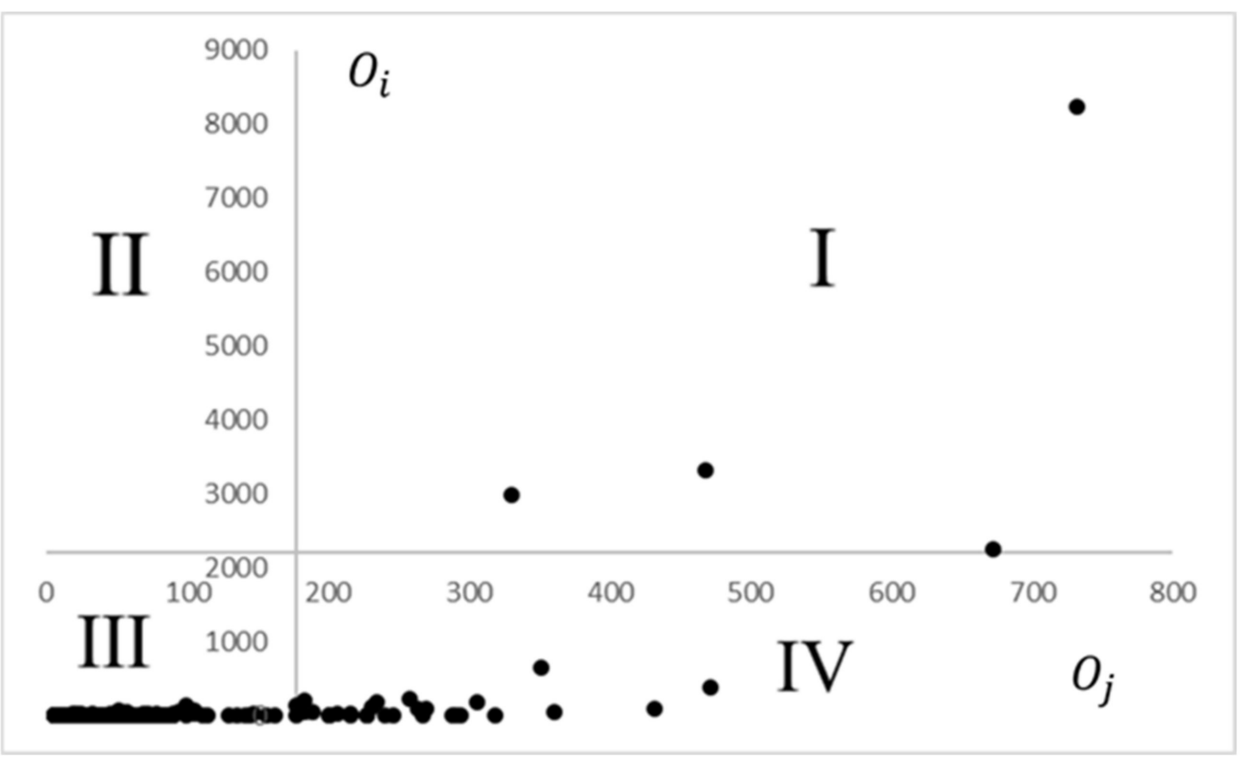

Figure 1. Classification of Chinese cities based on $O_{i}$ and $O_{j}$.

Through the above, analysis of the first- and second-level cities was performed. Although they are export-oriented, they still possess a high ability to attract, namely through external diffusion. Additionally, they are internally able to attract high-level city subsidiaries' control network in two ways. The third and fourth grades of provincial capital cities are generally introverted, and they do so by attracting a large number of subsidiaries and an embedded network to maintain a strong contact state. A general connection node city has a weak ability to attract subsidiaries, is in a state of weak connection, and has a high probability of disembedding from the network.

\subsection{Cyberspace Structure}

In order to intuitively show the spatial pattern of interconnection between cities, ArcGIS 10.2 software was used to analyze the nuclear density of the urban network (Figure 2). It was found that, based on the digital economy, the enterprise network connection presented a triangle structure with Beijing-Tianjin-Hebei, Yangtze River Delta, and Pearl River Delta as the vertex. The vertex of the triangle is the significantly high value area of the network core density, and the interior is the subcore area of the core density. That is, the internal and external relations of the three major urban agglomerations constitute the basic pattern of the urban network. Simultaneously, network density decreases step-by-step from the coastal areas to the inland areas. We further analyzed the hierarchical structure of the information flow network and divided the network into five levels (Figure 3) using the natural fracture method. The network characteristics of China's digital economy are mainly interpreted from the following aspects.

(1) Network polarization features are significant: The core network of the urban network of digital economy shows a radial pattern, with Beijing as the core and Beijing's control over the network further strengthened. Accordingly, Shanghai and Shenzhen have lost control of the network. Beijing now dominates in its number of corporate headquarters. Companies with headquarters in other cities have also been the first to set up subsidiaries in Beijing in order to gain outside knowledge and policy support.

(2) The network spatial pattern of dense east and sparse west: There are significant differences in urban network spatial distribution. Beginning from an overall view of 
the network, the network spatial distribution characteristics of dense east and sparse west are particularly obvious. Next, from the network level, the high-level network is mainly distributed to the east of the $\mathrm{Hu}$ Line, while the western region is usually part of the low-level network.

(3) The diffusion of subsidiaries is mainly the hierarchical diffusion between core node cities, and the diffusion effect between adjacent cities is not obvious: Among the topranking intercity connections, most of the connections are long-distance connections between core cities. For example, Beijing-Guangzhou, Beijing-Shanghai, and BeijingShenzhen are the three city pairs with the highest connectivity. The core network has been constructed by high-rise cities across regions, but the connection intensity between neighboring cities (especially medium and small cities) in the same region is generally weak. This indicates that the digital economic enterprises generally consider the developmental conditions and market potential of a city and pay less attention to the geographical distance between a city and its headquarters when conducting cross-regional expansions.

(4) The number of connections at different levels of the network: The number of connections between cities increases rapidly as the network level decreases. Among them, only $1.1 \%$ of the connections belong to the first-tier network, and $80 \%$ of the connections belong to the fifth-tier network. Most cities have a low connection intensity, and a few cities have concentrated high-intensity connections. The establishment of close links between core cities and extensive information exchange will lead to the Matthew effect of constant strength, which may render marginal cities locked, because they receive less heterogeneous information and gain less knowledge.

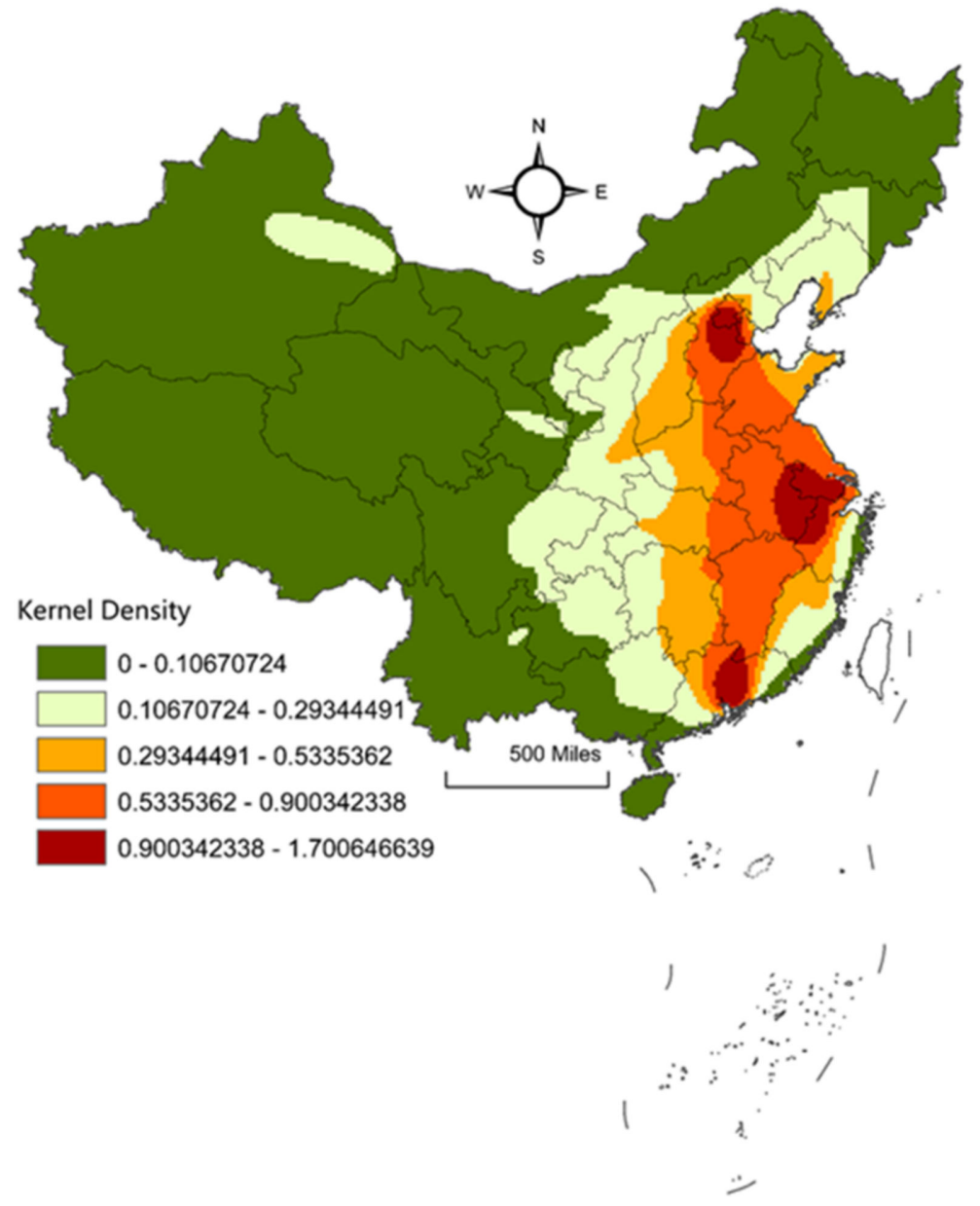

Figure 2. Kernel density of urban networks in China. 


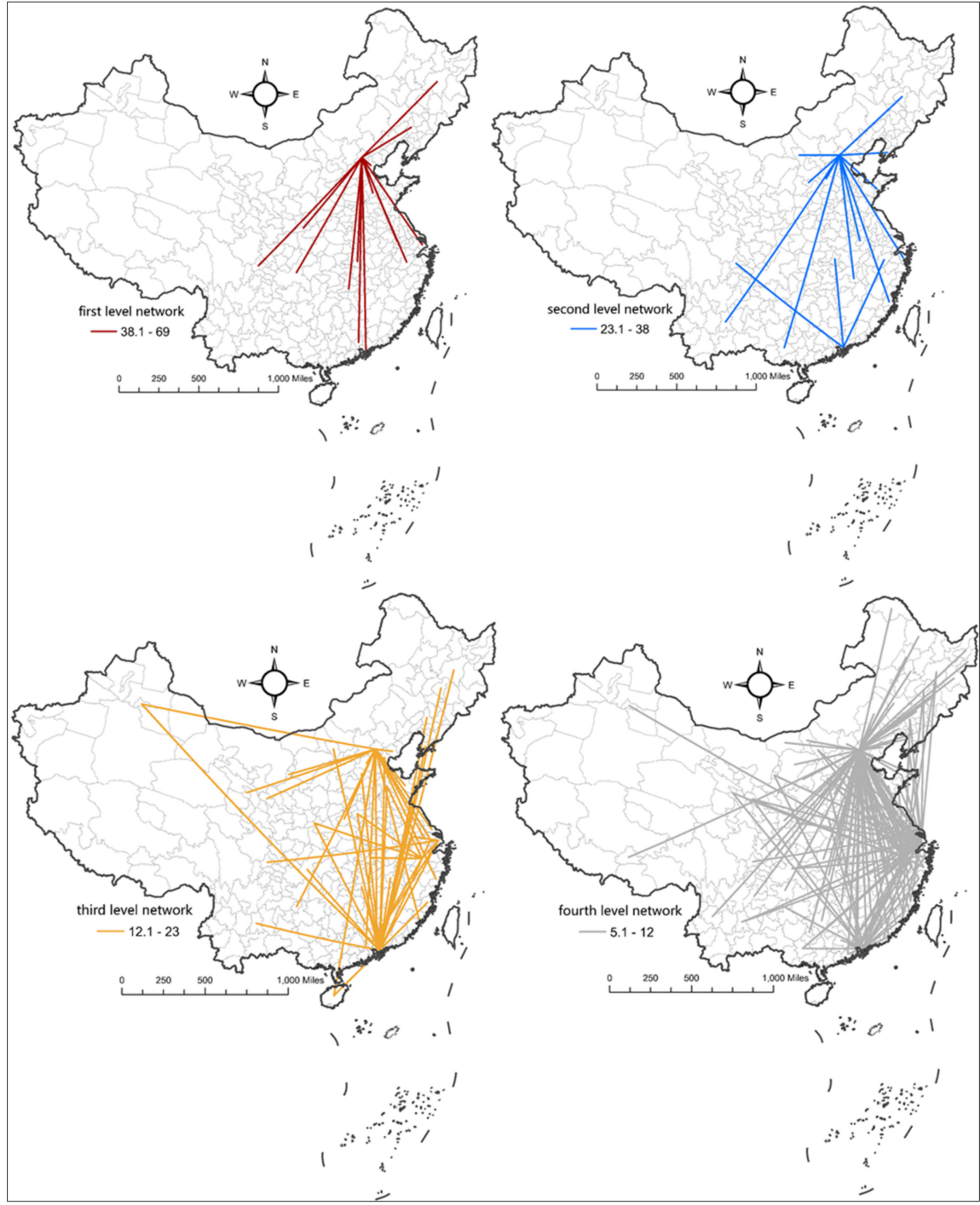

Figure 3. The structure of urban networks in China.

\section{Comparison of Network Characteristics of the Three Major Urban Agglomerations}

\subsection{Network Characteristics of the Three Major Urban Agglomerations}

More than $80 \%$ of the headquarters of new economic enterprises are located in the three major urban agglomerations of Beijing, Tianjin, Hebei, the Yangtze River Delta, and Pearl River Delta. According to the above research, the new economic enterprise network is greatly controlled by three major urban agglomerations. This explains why it is more beneficial to understand the spatial organization law of the digital economy on the scale of urban agglomeration by analyzing the internal network structure of three urban agglomerations and the characteristics of external contact network of urban agglomeration.

Initially, the network density and assignment index methods were used to analyze the overall network characteristics of the three major urban agglomerations. The network density was mainly determined by the number of corporate headquarters in the urban agglomeration and the intensity of subsidiary in the urban agglomeration, which reflects a close relationship within the urban agglomeration. The assignment index depends on the willingness of enterprises in the urban agglomeration to set up subsidiaries inside and outside the urban agglomeration and reflects the degree of cohesion or distribution of the urban agglomeration. The coefficient of variation is able to show the equilibrium degree of network control among cities in an urban agglomeration. 
As shown in Table 3, there is a large gap in network density among the three urban agglomerations of Beijing and Tianjin, the Yangtze River Delta, and Pearl River Delta. Comparatively speaking, the network density of the Pearl River Delta is the highest, while that of Beijing, Tianjin, and Hebei is much lower than that of the other two urban agglomerations. From the assignment index $\left(E-I_{\text {index }}\right.$ index $)$, the $E-I_{\text {index }}$ index of the three major urban agglomerations is close to 1; the highest is in Beijing-Tianjin-Hebei, and the lowest is in the Yangtze River Delta. This highlights that Beijing-Tianjin-Hebei enterprises tend to set up subsidiaries outside their urban agglomerations, while enterprises in the Yangtze River Delta tend to set up subsidiaries within their urban agglomerations. From the value coefficient of variation, the coefficients of variation of the three major urban agglomerations are all greater than 1 , therefore indicating that there is a significant difference in the ability of the urban organizational network within urban agglomerations, and urban development is uneven. The concentration of control power of the Beijing-Tianjin-Hebei network is the highest, and that of the Pearl River Delta is the lowest.

Table 3. Urban agglomeration network characteristic index.

\begin{tabular}{ccc}
\hline Urban Agglomeration & Network Density (D) & $\begin{array}{c}\text { Assignment Index } \\
\left(E-I_{\text {index }}\right)\end{array}$ \\
\hline Beijing-Tianjin-Hebei & 0.192 & 0.913 \\
Yangtze River Delta & 0.258 & 0.727 \\
Pearl River Delta & 0.639 & 0.853 \\
\hline
\end{tabular}

The above three indicators indicate that the internal network of the three major urban agglomerations is in a low-density state, the relationship between cities is loose, there is no obvious small group phenomenon in the three major urban agglomerations, the boundary constraint effect of urban agglomeration is insignificant, and more enterprises within the urban agglomeration have set up subsidiaries outside the urban agglomeration. Among the three major urban agglomerations, the development of Beijing-Tianjin-Hebei is the most uneven, and the Pearl River Delta is the most balanced. This may be due to the fact that digital economic enterprises prefer to establish their subsidiaries in areas where heterogeneous knowledge can be acquired, where the Beijing-Tianjin-Hebei region is strong in the field of electronic information technology, and the Yangtze River Delta region shows an advantage in e-commerce. In fact, it is far ahead of other regions, while the Pearl River Delta region has made good achievements in digital manufacturing. An urban agglomeration designed to establish contact with the outside world can obtain more external knowledge, which is conducive to improving the performance of enterprises.

\subsection{Characteristics of the External Relations of the Three Major Urban Agglomerations}

It is necessary to analyze the external contact characteristics of the three major urban agglomerations, because the digital economic network is principally controlled by Beijing-Tianjin-Hebei and the Yangtze River and Pearl River Deltas. As displayed in Figure 4, the Beijing-Tianjin-Hebei outward diffusion and inward attractor enterprises show obvious spatial stratification characteristics. In terms of external diffusion, the Yangtze River Delta is the preferred place to set up subsidiaries, and the number of subsidiary enterprises is much larger than that of other urban agglomerations. The middle reaches of the Yangtze River, Pearl River Delta, and the Shandong Peninsula are in the second gradient of the external diffusion of Beijing-Tianjin-Hebei enterprises. Chengdu-Chongqing, the Central Plains, and the western bank of the Taiwan Strait are in the third gradient. Other urban agglomerations receive relatively few subsidiaries from Beijing-Tianjin-Hebei. It is more convenient to attract internally; the number of subenterprises from the Yangtze River Delta are still unique. The Pearl River Delta is in the second echelon, and there are fewer subsidiaries from other urban agglomerations. 


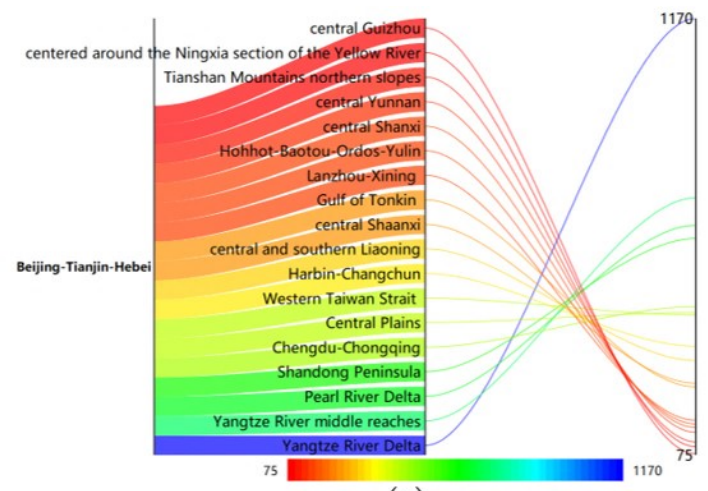

(a)

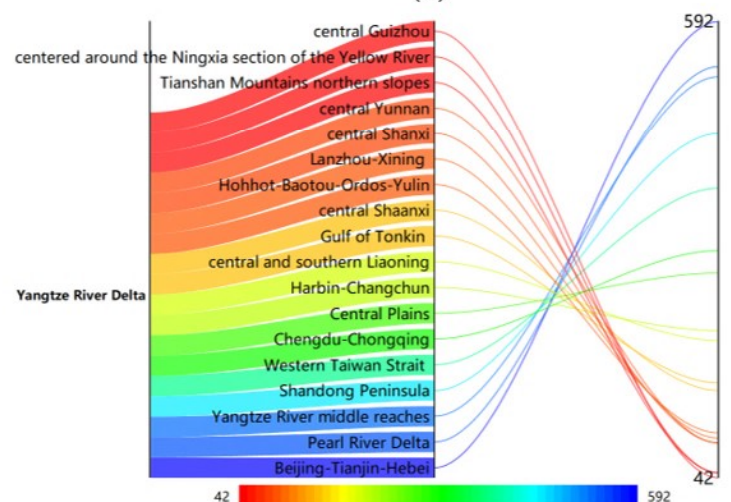

(c)

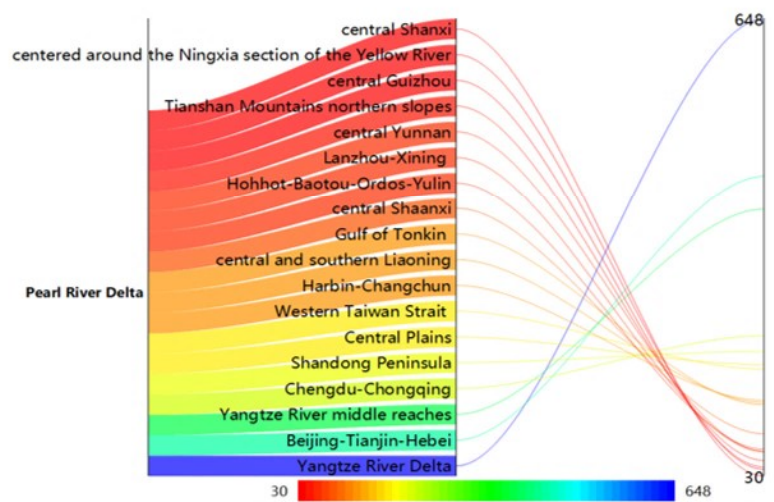

(e)

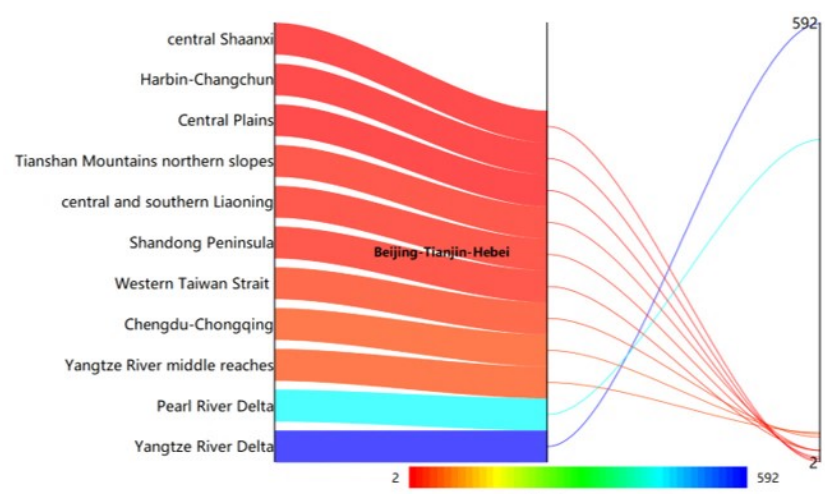

(b)

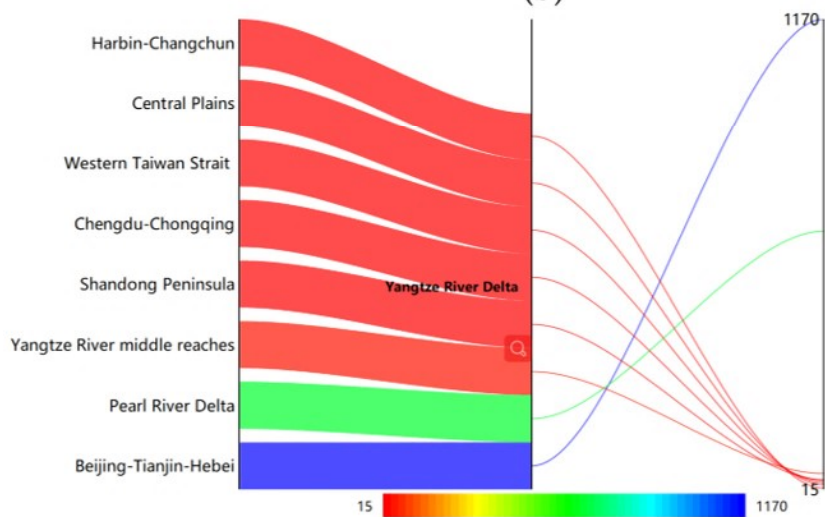

(d)

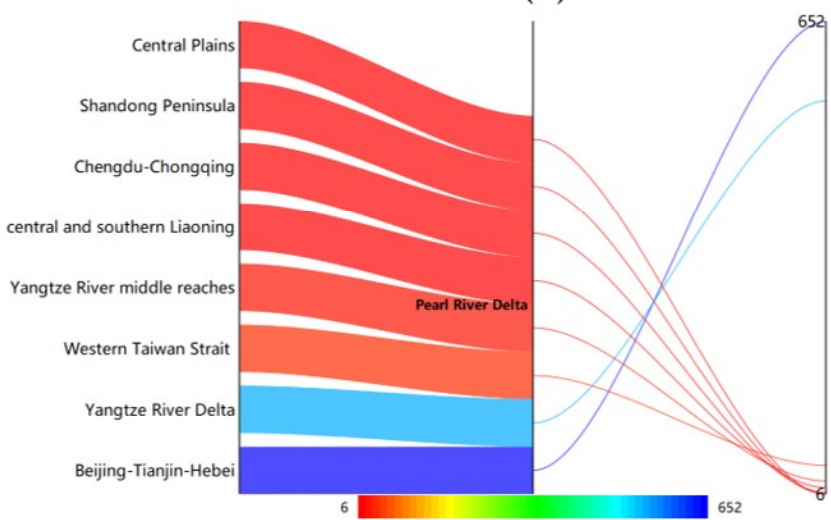

(f)

Figure 4. The external contact characteristics of the three urban agglomerations: (a) Beijing-TianjinHebei urban agglomeration diffusion subenterprises; (b) Beijing-Tianjin-Hebei urban agglomeration attracts subenterprises; (c) Yangtze River Delta urban agglomeration diffusion subenterprises; (d) Yangtze River Delta attracts subenterprises; (e) Pearl River Delta urban agglomeration diffusion subenterprises; (f) Pearl River Delta attracts subenterprises.

The spatial pattern of external diffusion in the Yangtze River Delta is relatively balanced, showing an isometric decreasing pattern with the largest number of enterprises spreading to Beijing, Tianjin, and Hebei. These are followed by the Pearl River Delta and the Yangtze River, and, subsequently, by the Shandong Peninsula and the western bank of the Taiwan Strait. The Central Plains, Chengdu, and Chongqing have also attracted a considerable number of subsidiaries from the Yangtze River Delta. In terms of attracting enterprises, the most subsidiaries have been established in Beijing, Tianjin, and Hebei, followed by the Pearl River Delta.

The agglomeration effect of external diffusion in the Pearl River Delta is also prominent, with the largest number of subenterprises established in the Yangtze River Delta. This 
is followed by Beijing-Tianjin-Hebei and the middle reaches of the Yangtze River. Most attracted subenterprises come from the Yangtze River Delta, and they are followed by Beijing-Tianjin-Hebei.

In conclusion, the Yangtze River Delta region has the strongest ability to attract subsidiaries of digital economic enterprises. Beijing-Tianjin-Hebei and the Pearl River Delta have set up the most subenterprises in the Yangtze River Delta, and this number is much larger than that of other urban agglomerations. China's digital economy is dominated by private enterprises, and the Yangtze River Delta has made remarkable achievements in China's market-oriented reform. This is especially evident in Shanghai, the financial center of China, where it may be convenient for the digital economy to set up subsidiaries in the Yangtze River Delta. The Yangtze River Delta is developing rapidly in the field of e-commerce, and the establishment of subsidiaries here can obtain relevant knowledge. Interestingly, in terms of geographical location and space, the Yangtze River Delta is located between Beijing-Tianjin-Hebei and the Pearl River Delta, which may make the Yangtze River Delta a bridge for the exchange of information between Beijing-Tianjin-Hebei and the Pearl River Delta.

\subsection{Urban Agglomeration Network Organization Model}

The connection between the urban agglomeration network and the outside world is primarily through core cities, where it spreads outward and attracts subsidiaries inwardly. Simultaneously, a core city is also the hub of the internal network of an urban agglomeration. The ways in which the three major urban agglomerations communicate with the outside world are different. The organization of the internal network is also different, which can be divided into three different spatial organization modes: single center, dual core, and multicenter. The specific spatial connotation is as follows:

(1) The single-center model takes a single city as its core. Among them, the core city is in an absolute leading position, which is not only the medium of communication between the urban agglomeration and the outside world, but also the connection hub within the urban agglomeration. The Beijing-Tianjin-Hebei urban agglomeration is an excellent example of this characteristic. Beijing is the absolute core of the Beijing-Tianjin-Hebei urban agglomeration, and it has established close ties with other urban agglomerations through radiation and diffusion. It is the only hub with internal links in its urban agglomeration. It is closely related to numerous cities, while the links between other cities are very sparse; only the connection between Xingtai and Shijiazhuang exists.

(2) In the dual-core organization model, there are two core cities: the two core cities leading urban agglomeration and the internal network organization. The Pearl River Delta is representative of this model, where Shenzhen and Guangzhou act as external contact hubs, but in different ways. Shenzhen coexists with the outside world in terms of external diffusion and attracting subsidiary, while Guangzhou achieves external contact mainly by attracting outside subsidiaries. The Pearl River Delta is controlled by Shenzhen and Guangzhou. Shenzhen and Guangzhou are the core cities within this urban agglomeration, and they are closely related to other cities, yet there are also few links between other cities. There are only two city pairs: Zhuhai-Zhongshan and Shantou-Zhuhai.

(3) In the multicenter model, there are more than two core cities with external relations and internal organizations. The Yangtze River Delta is a typical polycentric structure. Hangzhou and Shanghai are the core cities connected with the outside world in the Yangtze River Delta. Shanghai set up more subsidiaries in the Yangtze River Basin, Beijing-Tianjin-Hebei, and the western bank of the Taiwan Strait, while the connection with the central and western urban agglomeration is mainly achieved through Hangzhou. Shanghai, Hangzhou, and Nanjing are the core node cities of the Yangtze River Delta's internal relations. As the provincial capitals of Jiangsu and Zhejiang, Nanjing and Hangzhou have established close ties with other cities in their 
provinces. Shanghai is related to most cities in the urban agglomeration, and the three core cities are also closely related to each other. The network is still dominated by vertical connections. However, there are relatively few links between other cities, those being Wuxi, Suzhou, Changzhou, and other Jiangsu Province cities.

\section{Discussion and Conclusions}

\subsection{Discussion}

We discuss the reasons and assumptions with respect to the results of this study. The key to urban network research lies in the construction of feasible relational datasets. In the two pieces of literature compared in this study, the enterprise data covers the major enterprises in China's APS and manufacturing sectors, so they are comparable on a national scale.

Based on the data of the new economic top 500 enterprises, the study of the digital economic urban network found that China's urban network has undergone significant changes. Compared with APS enterprises and listed companies [45-47], the urban network of digital economy has become more polarized. Specifically, Beijing holds a stronger central position, far higher than that of other cities, and sits at an absolute dominant position in the urban network. Furthermore, the number of high-level cities is very small, with only nine cities in the first three tiers and most of the others in the fifth tier. Finally, the core network is constructed through the connection between a few high-level cities. A possible reason for the greater polarization of digital economic city networks is that, although digital technology makes the marginal cost of information transmission very low, there is still a large fixed-input cost of the information infrastructure [57]. Additionally, the development of digital technology is a double-edged sword; it is conveyed in low-cost, rapid-transfer forms of information. Concurrently, this has led to a huge, redundant information release, fostered the conveyance of tacit knowledge, and called for the direct and accurate access to real, undistorted information. It is capable of taking full advantage of the superiority of an area rich in professional, high-quality talent [25]. Moreover, as a new economic form, the digital economy still has many nonstandardized technologies and management modes, so it requires spatial agglomeration [57].

Chinese cities may be reshuffled in this era of the digital economy, as it will provide a window of opportunity for urban development. Some cities are rising rapidly, and others are declining due to the digital economy. Specifically, the positions of Beijing, Hangzhou, and Chengdu in the digital economic network have significantly increased, while the positions of traditional heavily industrial cities, such as Wuhan, Shenyang, and Chongqing, have significantly decreased. A possible reason lies in the fact that besides institutional factors, the industrial base of the digital economy determines the position of cities within the digital economic city network. China's leading industrial clusters of software, integrated circuits, and communication networks in the Zhongguancun Science and Technology Park provide fertile ground for the development of Beijing's digital economy [29]. Regarding Hangzhou, the rapid development of the digital economy, to a large extent, depends on the height of the internet application. This is especially true in the field of electronic commerce, which has made remarkable achievements. Hangzhou is one of China's e-commerce pilot cities, a center for electronic government affairs, electronic commerce construction (started earlier), an improved foundation, and level of economic development in the national front row. E-commerce Alibaba is the star enterprise in the field of electronic commerce, and it acts as a trigger or incubator [53]. As an important economic growth pole in western China, Chengdu is the national communication hub city and the first $5 \mathrm{G}$ pilot city. It has laid out new infrastructure construction in the country, and presently, Chengdu possesses the first dedicated channel in southwest China to carry the business of an international dedicated internet line. Dedicated internet access is promoting the rapid development of the digital economy in Chengdu [54]. Although Wuhan has a solid manufacturing foundation, its economy is mostly composed of large, state-owned enterprises, and the scale and number of private enterprises still needs to be improved. 
Under the new situation of a market-oriented digital economy, state-owned enterprises reveal that Wuhan's economy lacks vitality [27]. Of course, this is also the problem faced by the vast majority of heavily industrial cities. Hangzhou's status in the network surprisingly exceeds that of Shanghai, the leading city in the Yangtze River Delta; this reflects the same conclusions as discovered in the research results of Cao et al. [27], but it does not mean that Hangzhou has surpassed Shanghai in the digital economic era. It should be noted that Shanghai has a much higher position than Hangzhou in the global digital city network [18].

Although the digital economy has reshaped China's urban network structure, the old urban pattern may still play a dominant role in the new system. Specifically, compared with the urban network of listed companies and APS enterprises, lower-level cities are still locked in the lower level, because it is difficult to realize any transition of network rank. Furthermore, the network structure has similarities, and the digital economic urban network presents the spatial pattern of dense east and sparse west. Finally, the performances of urban agglomerations are very similar. The network density of urban agglomerations in the Yangtze River and Pearl River Deltas is much higher than that in Beijing-Tianjin-Hebei. Beijing-Tianjin-Hebei presents a single center structure, the Pearl River Delta presents a dual-core structure, and the Yangtze River Delta presents a multicenter structure [48,49]. The possible reasons for this are the digital economy did not arise out of thin air, more digital economic enterprises occur by traditional enterprise transformation [27], numerous deep-seated reasons, China's unbalanced economic development with respect to globalization, marketization of fiscal decentralization, the eastern coastal areas having become the center of the economic growth, issues due to the historic accumulation of the development gap, and eastern Chinese cities typically have a number of better research universities, improved transportation infrastructure, and cultural facilities. For example, regions with the highest levels of digital economic connectivity in China include Shanghai, Beijing, and Jiangsu, and they just so happen to be home to the country's top universities [28].

Network diffusion has been, to a great degree, hierarchical diffusion between core nodes, but the diffusion effect between neighboring cities is not very clear. This has manifested in three aspects. First, long-distance connections between core cities are the main links among top cities. For example, Beijing-Guangzhou, Beijing-Shanghai, and Beijing-Shenzhen are the three city pairs with the highest connection degree. Secondly, most cities enter the network by establishing links with core cities (Beijing, Shenzhen, Shanghai, and Hangzhou), but fewer with regional, central cities. Finally, the indices of the three urban agglomerations all tend to 1, with a tendency to establish subsidiaries outside urban agglomerations. One possible reason is that digital technology enables subsidiaries to overcome the limitations of distance by allowing them to locate in the most advantageous cities [58]. Interestingly, the Yangtze River Delta region receives the most subenterprises. The digital economy in the Yangtze River Delta is developing rapidly, and subenterprises embedded in it can benefit from knowledge spillover. By contrast, as private enterprises in the digital economy, they tend to establish subsidiaries in areas with a high marketization degree [59].

\subsection{Conclusions}

The digital economy is rising, and the influence of digital enterprises is increasing. This paper explores the network structure of China's digital economy city. By comparing it with APS enterprises, Fortune 500 enterprises, and listed companies $[29,47,48]$, it is found that the digital economy has reshaped the characteristics of China's urban network, the network is more polarized, some cities begin to rise, and some cities show a decline trend; this is one of the main contributions of this study. Secondly, from the perspective of enterprises, this paper uses a more direct and accurate headquarter-subsidiary association model to provide a more accurate reflection of China's urban network structure. This paper provides an empirical case for the impact of the digital economy on urban networks in China. The main conclusions and implications are as follows: 
(1) Based on the data of the top 500 enterprises of the new economy, it is found that the urban network of the digital economy in China has undergone obvious changes, and the urban network of the digital economy has become more polarized. This indicates that digital economy may lead to China's increasingly unbalanced development; a few cities occupy the high ground of the digital economy, where they will be able to control digital economy related resources, including big data, senior personnel, and others. This requires the central government to make policies to support the digital economy development of cities in the west of China, avoiding the gap between the eastern China and th western China from widening in the digital economy.

(2) Cities in China are reshuffled in the era of digital economy. Cities such as Beijing, Hangzhou, and Chengdu, which have the industrial foundation of the digital economy, perform better in the network. Some heavily industrial cities, such as Wuhan, Shenyang, and Chongqing, have shown a disadvantage in the era of digital economy probably due to the difficulty of transformation. The successful experiences of Hangzhou and Chengdu indicate that appropriate local policies will be conducive to the early development of the digital economy.

(3) The digital economy has reshaped China's urban network structure, but the original urban pattern still plays a dominant role in the new urban network. The network spatial pattern of dense east and sparse west still exists, and provincial capitals and subprovincial cities still play a higher role in the network than ordinary cities. Although the digital economy gives cities the opportunity to achieve path breakthroughs, which means cities of all sizes are likely to have good growth opportunities, the economic base of cities still plays an important role, and regional central cities will continue to be the primary sectors for the development of the digital economy.

(4) The diffusion of subsidiaries is mainly the hierarchical diffusion between core node cities, and the diffusion effect between adjacent cities is not obvious. Geographical proximity has a low constraint on subsidiaries diffusion. Backward areas are able to establish cross-regional links and obtain necessary resources and markets from other cities. Therefore, local governments should not only emphasize the building of digital clusters, but also attach importance to strengthening the connection between local enterprises and digital clusters of different scales, such as regional and national. Suitable industrial resources and potential markets can be sought in a broader production network.

This work has certain limitations, which provide possible opportunities for future research. Firstly, due to the difficulty in obtaining the time information of the establishment of enterprise subsidiaries, this paper only used the data of a single year to analyze the characteristics of the urban network of the digital economy, resulting in the lack of a dynamic evolution analysis of the urban network and the consistency of the research results to a certain extent. There will always be agglomeration in the early stage of a new economic form. With the passage of time, there may be a trend of diffusion. Therefore, it is necessary to track and study digital economic enterprises to make the impact of digital economy on urban network more universal. Secondly, because the specific contact strength between the headquarters and subsidiaries is difficult to accurately measure, it is too simple to divide them into two levels only by the type of subsidiaries, which may strengthen or weaken the real contact strength between cities. Third, this paper only sampled the top 500 enterprises to represent the spatial networking organization of China's new economy, which may lead to one-sidedness. China's digital enterprises develop rapidly; ignoring small and medium-sized enterprises may make the urban network of the digital economy sparse. In addition, with the new changes of urban network structure in the digital economy, we need to further explore its influencing factors and mechanisms in the future. Finally, it is worth noting that most of China's digital enterprises are transformed from traditional industries, and it is difficult to quantify their digitization level. That may bring about errors in the impact of digital economy on urban networks. 
Author Contributions: B.C., the first author, completed the draft manuscript, and H.Z., the correspondent author, contributed to the theoretical foundation and conclusions, and provided enlightening suggestions for the research ideas and meaningful guidance for the improvement of the article's academic quality. All authors have read and agreed to the published version of the manuscript.

Funding: This research was funded by [National Natural Science Foundation of China] grant number [42071152].

Institutional Review Board Statement: Not applicable.

Informed Consent Statement: Not applicable.

Data Availability Statement: We got the location information of the headquarters and branches of the China's Top 500 New Economy Enterprises in 2020 through the inquiry of the official website of these enterprises.

Acknowledgments: We appreciate the two anonymous reviewers for their excellent comments and to the editors for their help in publishing the article.

Conflicts of Interest: All authors declare no conflict of interest.

\section{References}

1. Beaverstock, J.V.; Smith, R.G.; Taylor, P.J. World-city network: A new metageography? Ann. Assoc. Am. Geogr. 2000, 90, 123-134. [CrossRef]

2. Taylor, P.J.; Derudder, B.; Faulconbridge, J.; Hoyler, M.; Ni, P.F. Advanced producer service firms as strategic networks, global cities as strategic places. Econ. Geogr. 2014, 90, 267-291. [CrossRef]

3. Alderson, A.S.; Beckfield, J.; Sprague-Jones, J. Intercity relations and globalization: The evolution of the global urban hierarchy, 1981-2007. Urban Stud. 2010, 47, 1899-1923. [CrossRef]

4. Derudder, B.; Taylor, P.J.; Hoyler, M.; Ni, P.F.; Liu, X.J.; Zhao, M.X.; Shen, W.; Witlox, F. Measurement and interpretation of connectivity of Chinese cities in world city network. Chin. Geogr. Sci. 2010, 23, 261-273. [CrossRef]

5. Mahutga, M.C.; Ma, X.; Smith, D.A.; Timberlake, M. Economic globalization and the structure of the world city system: The case of airline passenger data. Urban Stud. 2010, 47, 1925-1947. [CrossRef]

6. Rozenblat, C. Opening the black box of agglomeration economies for measuring cities' competitiveness through international firm networks. Urban Stud. 2010, 47, 2841-2865. [CrossRef]

7. Huang, X.D.; Ma, H.T.; Miao, C.H. Connectivity characteristics for city networks in China based on innovative enterprises. Acta Geogr. Sin. 2021, 76, 835-852. (In Chinese)

8. Pan, F.H.; Bi, W.K.; Lenzer, J.; Zhao, S. Mapping urban networks through inter-firm service relationships: The case of China. Urban Stud. 2017, 54, 3639-3654. [CrossRef]

9. Wall, R. Gulfworld: Corporate Profiles and Networks of Gulf Cities. In Al Manakh 2; Stichting Archis and Pink Tank: New York, NY, USA, 2010.

10. Arthur, W.B. The Nature of Technology: What It Is and How It Evolves; Simon and Schuster: New York, NY, USA, 2009.

11. Arthur, W.B. Complexity and the Economy; Oxford University Press: Oxford, UK, 2014.

12. Hoyler, M.; Watson, A. Framing city networks through temporary projects: (Trans)national film production beyond 'Global Hollywood'. Urban Stud. 2018, 56, 943-959. [CrossRef]

13. Martinus, K.; Sigler, T.J.; Searle, G.; Tonts, M. Strategic globalizing centers and sub- network geometries: A social network analysis of multi-scalar energy networks. Geoforum 2015, 64, 78-89. [CrossRef]

14. Gray, M.; Kovacova, M. Internet of Things Sensors and Digital Urban Governance in Data-driven Smart Sustainable Cities. Geopolit. Hist. Int. Relat. 2021, 13, 107-120.

15. Campbell, E.; Bilan, Y. Robotic Wireless Sensor Networks, Internet of Things-enabled Sustainability, and Real-Time Advanced Analytics in Cyber-Physical System-based Smart Factories. Econ. Manag. Financ. Mark. 2021, 16, 68-80.

16. Kovacova, M.; Lewis, E. Smart Factory Performance, Cognitive Automation, and Industrial Big Data Analytics in Sustainable Manufacturing Internet of Things. J. Self-Gov. Manag. Econ. 2021, 9, 9-21.

17. Pelau, C.; Dabija, D.C.; Ene, I. What Makes an AI Device Human-Like? The Role of Interaction Quality, Empathy and Perceived Psychological Anthropomorphic Characteristics in the Acceptance of Artificial Intelligence in the Service Industry. Comput. Hum. Behav. 2021, 122, 106855. [CrossRef]

18. Tranos, E.; Kourtit, K.; Nijkamp, P. Digital urban network connectivity: Global and Chinese internet patterns. Pap. Reg. Sci. 2014, 93, 409-428. [CrossRef]

19. Wheeler, D.C.; O'Kelly, M.E. Network Topology and City Accessibility of the Commercial Internet. Prof. Geogr. 1999, 51, 327-339. [CrossRef]

20. Townsend, A.M. The Internet and the rise of the new network cities, 1969-1999. Environ. Plan. B 2001, 28, 39-58. [CrossRef]

21. Zook, M.A. Old Hierarchies or New Networks of Centrality? The Global Geography of the Internet Content Market. Am. Behav. Sci. 2001, 44, 1679-1696. [CrossRef] 
22. Negroponte, N.; Harrington, R.; McKay, S.R.; Christian, W. Being digital. Comput. Phys. 1997, 11, 261-262. [CrossRef]

23. Cairncross, F. The Death of Distance 2.0: How the Communications Revolution Will Change Our Lives; Texere Publishing Limited: Knutsford, UK, 2001.

24. Leamer, E.E.; Storper, M. The economic geography of the internet age. J. Int. Bus. Stud. 2001, 32, 641-665. [CrossRef]

25. Storper, M.; Venables, A.J. Buzz: Face-to-Face Contact and the Urban Economy. CEP Discuss. Pap. 2003, 4, $351-370$.

26. Jiao, S.T.; Sun, Q.B. Digital economic development and its impact on economic growth in China: Research based on the prespective of sustainability. Sustainability 2021, 13, 10245. [CrossRef]

27. Cao, Q.; Shen, L.Z.; Zhen, F. Spatial evolution of China's internet enterprises and the characteristics of city network. Hum. Geogr. 2018, 33, 97-105.

28. Hao, R.; Wei, Z. Fundamental causes of inland-coastal income inequality in post-reform China. Ann. Reg. Sci. 2010, 45, 181-206. [CrossRef]

29. Zhao, X.M.; Liu, X.; Derudder, B.; Zhong, Y.; Shen, W. Mapping producer services networks in mainland Chinese cities. Urban Stud. 2015, 52, 3018-3034. [CrossRef]

30. Zhou, W.; Wang, M.F. Chinese Urban System Structure based on "Internet Plus" Economy. Urban Dev. Stud. 2018, 25, 9-15.

31. Granoveter, M. Economic action and social structure: The problem of embeddedness. Am. J. Sociol. 1985, 91, 481-510. [CrossRef]

32. Uzzi, B. The source and consequences of embeddedness for the economic performance of organizations: The network effect. Am. Sociol. Rev. 1996, 61, 674-698. [CrossRef]

33. Nie, C.Q. Study on Urban Network Spatial Structure Evolution of the Pan-Yangtze River Delta Based on the Corporate Organization Network; East China Normal University: Shanghai, China, 2018. (In Chinese)

34. Hall, P.G. The World Cities; Heinemann: London, UK, 1966.

35. Friedmann, J. The World City Hypothesis. Dev. Chang. 1986, 17, 69-83. [CrossRef]

36. Sassen, S. The global City. New York, London, Tokyo. Political Sci. Q. 2001, 107, 370-371.

37. Castells, M. The Rise of Network Society. Contemp. Sociol. 2000, 26, 725-726.

38. Taylor, P.J. Urban hinterworlds: Geographies of corporate service provision under conditions of contemporary globalisation. Geography 2001, 86, 51.

39. Taylor, P.J. Specification of the world city network. Geogr. Anal. 2001, 33, 181-194. [CrossRef]

40. Taylor, P.J.; Derudder, B. World City Network: A Global Urban Analysis, 2nd ed.; Routledge: London, UK, 2015.

41. Rozenblat, C.; Pumain, D. Firm Linkages, Innovation and the Evolution of Urban Systems; Taylor, P.B., Ed.; Taylor \& Francis Inc.: New York, NY, USA, 2007.

42. Krätke, S. Network analysis of production clusters: The Potsdam/Babelsberg film industry as an example. Eur. Plan. Stud. 2002, 10, 27-54. [CrossRef]

43. Lu, J.Y.; Sun, D.Q. Spatiotemporal Evolution and complexity of urban networks in China, 1978-2019: An enterprise linkages perspective. Complexity 2021, 2021, 9931985. [CrossRef]

44. Wall, R.S.; Van der Knaap, G.A. Sectoral differentiation and network structure within contemporary worldwide corporate networks. Econ. Geogr. 2011, 87, 267-308. [CrossRef]

45. Csomós, G. Cities as command and control centres of the world economy: An empirical analysis, 2006-2015. Bull. Geogr. Socio-Econ. Ser. 2017, 38, 7-26. [CrossRef]

46. Raźniak, P.; Dorocki, S.; Winiarczyk-Raźniak, A. Permanence of economic potential of cities based on sector development. Chin. Geogr. Sci. 2017, 27, 123-136. [CrossRef]

47. Zhao, X.Z.; Su, J.; Chao, J.; Liu, X.Q.; Li, T.S.; Rui, Y.; Yang, J. The character and economic preference of city network of China: A Study Based on the Chinese Global Fortune 500 Enterprises. Complexity 2020, 2020, 4312578. [CrossRef]

48. Jiang, X.; Yang, Y.C.; Wang, S.L.; Wang, M.M.; Yang, Y.B. Spatial structure of Chinese intercity network based on the data of listed companies. City Plan. Rev. 2017, 41, 18-26. (In Chinese)

49. Li, Y.; Sun, Y.; Yao, S.M. Urban network linkages of Chinese urban agglomerations based on an analysis of the Fortune China Top 500 Enterprises. Geogr. Res. 2020, 39, 1548-1564. (In Chinese)

50. Zhao, M.X.; Li, Z.F.; Zhong, Y.; Derudder, B. Polycentric network topology of urban agglomerations in China. Prog. Geogr. 2016, 35, 376-388. (In Chinese)

51. Liu, W.D. Development of the Internet in China: Spatial characteristics and implications. Geogr. Res. 2002, 21, 347-356.

52. Wang, M.F.; Ning, Y.M. The network advantage of cities: An analysis of spatial structure and node accessibility of Internet backbones in China. Geogr. Res. 2006, 25, 193-203.

53. Xu, M.Z.; Lv, T. Zhejiang practice of digital economy: Development process, model characteristics and experience enlightenment. China Dev. Obs. 2019, 24, 67-71. (In Chinese)

54. Gao, X.L.; Xia, Y. Research on "New Infrastructure" facilitating the rapid development of Chengdu's digital economy. J. Chengdu Inst. Public Adm. 2020, 129, 36-40.

55. Shi, W.T.; Du, D.B.; Yang, W.L. The flow network of chinese scientists and its driving mechanisms based on the spatial development path of CAS and CAE academicians. Sustainability 2019, 11, 5938. [CrossRef]

56. Ma, H.T. Triangle model of Chinese returnees: A tentative method for city networks based on talent flows. Geogr. Res. 2017, 36, 161-170. 
57. Lu, M.; Xiang, K.H. Solving the Dilemma between Efficiency and Balance: On China's Regional Development Strategy. Comp. Econ. Soc. Syst. 2014, 4, 16. (In Chinese)

58. Zhang, X.; Yu, F.Z.; Xu, L.J. Spatial structure of urban networks in China based on the perspective of cultural industry enterprise networks. Prog. Geogr. 2020, 39, 78-90. [CrossRef]

59. Zhang, S.B.; Kang, B.C.; Zhang, Z.X. Evaluation of business environment in Chinese provinces: Indicator system and quan-titative Analysis. Econ. Manag. 2020, 4, 5-19. (In Chinese) 